Nasadyuk C. M.

Institute of Cell Therapy, Kyiv, Ukraine

e-mail: nasadyukch@gmail.com

\title{
CELL TECHNOLOGIES IN REPRODUCTOLOGY, OBSTETRICS AND GYNECOLOGY
}

\section{ABSTRACT}

The review describes the current trends of the development of cell and gene technologies in obstetrics, gynecology and reproductive medicine. The strategies of allogeneic and autologous hematopoietic stem cell transplantation in the myeloablative treatment of germinal tumors and breast cancer are considered, as well as adoptive immunotherapy, modern approaches to the treatment of female and male infertility, and also prenatal cell and gene therapy. The problems and achievements in uterus transplantation are described, as well as the successes in the cryopreservation of reproductive cells and tissues.

KEY-WORDS: stem cells, infertility, prenatal stem cells transplantation, reproductology.

With the development of biotechnologies and deeper understanding of the mechanism of regenerative action of stem cells in recent years, the scientists around the world are creating approaches to the use of cellular technologies in reproductive medicine, obstetrics and gynecology. Efforts of physicians in this area are primarily aimed at overcoming infertility, treatment of oncological diseases of the genital glands in men and women, prenatal correction of fetal anomalies by means of cell and gene technologies $[7,8,9,37,39]$. The confirmed possibility of the exchange of the cells between the body of mother and fetus through the placenta is of great interest, so that the mother may develop microchimerism [39]. There is also evidence of remedial influence of the fetus stem cells on the mother's body, all of this complements the existing knowledge about the interaction of the mother and fetus during pregnancy and explains the observation of the positive effect of pregnancy on the course of a number of chronic diseases in women [38]. In recent years, significant progress in the cryopreservation of reproductive cells and tissues for subsequent reimplantation to restore reproductive function in cancer patients of reproductive age after chemotherapy and irradiation has been achieved [15].

Thus, to date, the therapeutic use of stem cells in obstetrics, gynecology and reproductive medicine can be viewed in the following areas:

- Hematopoietic stem cells transplantation and adoptive immunotherapy in the treatment of solid tumors of female reproductive system [36, 39, 40, 41].

- Treatment of female and male infertility $[2,4,11]$.

- Creation of tissue-engineered constructs for gynecology [1, 10, 14].

- Prenatal stem cell transplantation and gene therapy for intrauterine treatment of congenital genetic diseases of the fetus [7, 8, 18, 38]

- Banking and approaches to the clinical application of the endometrial stem cells, mammary and amniotic fluid stem cells $[5,16,23]$

- $\quad$ Cryopreservation of reproductive cells and tissues $[3,4,15]$.

- $\quad$ Reconstructive breast surgery [30].

\section{HEMATOPOIETIC STEM CELLS TRANSPLANTA- TION AND ADOPTIVE IMMUNOTHERAPY IN THE TREATMENT OF SOLID TUMORS OF FEMALE REPRODUCTIVE SYSTEM.}

Based on the results of experimental and early clinical trials of the 1980s high-dose chemotherapy with autologous hematopoietic stem cells transplantation was adopted by many oncologists as a potential treatment of a number of solid tumors, especially malignant diseases of the female reproductive glands [36,38]. Hematopoietic stem cell transplantation is also considered in vaccination protocols in oncology and as a source of cytokines for the posttransplantation immunorehabilitation. Dendritic cells are studied for the possible application in the treatment of advanced ovarian cancer. An alternative approach of allogeneic transplantation of hematopoietic stem cells after standard myeloblative and nonmyeloablative conditioning regimens was proposed, which is seen as a new adoptive immunotherapy of non-hematological malignancies $[39,40]$. At the same time, the first randomized clinical trial comparing high-dose chemotherapy with peripheral blood hematopoietic stem cells transplantation and chemotherapy, based on the use of platinum, that covered 149 patients with untreated ovarian cancer, showed no statistically significant differences in both groups [31].

According to the literary data, the effect of «graft-versus-tumor» was noted in a number of patients with renal cell carcinoma, breast cancer, ovarian cancer, pancreatic cancer, colorectal cancer after allogeneic hematopoietic stem cell transplantation [9]. Several authors have also reported the potentiation of the antitumor effect by the donor lymphocytes infusion in metastatic breast cancer, kidney, prostate, colorectal and pancreatic cancer [43].

In another study the positive effect of the use of the human umbilical cord blood mesenchymal stem cells in as a method of gene delivery 
of interleukin-21 (IL-21) in the treatment of ovarian cancer in mice was reported. IL-21-mesenchymal stem cells from umbilical cord blood were injected intravenously to mice with ovarian cancer A2780. The effectiveness of this approach was confirmed by the decrease of the tumor size and increased survival of the animals [20].

On the line of nude $B A L B / C$ mice with engrafted mammary tumor derived from MDA-MB-231 cells, the effect of amniotic membrane epithelial stem cells transplantation was studied. It was shown, that cultivation of amniotic membrane epithelial stem cells and MDA-MB-231 cells in the ratio of $1: 4$ or $1: 8$ (tumor stem cells to cells) inhibited the growth of breast cancer cells for 67,29 and $67,33 \%$ respectively. In contrast to mice treated with 5-fluorouracil, antitumor effect of amniotic membrane stem cells was not accompanied by any side-effects (weight loss, death, hemorrhages) [6, 23].

There is also evidence that bilateral transplantation of adipose tissue stem cells directly into the ovaries contributed to the preservation of reproductive function in mice after chemotherapy [45].

Future strategies for the use of hematopoietic stem cells in gynecological oncology are based on the capabilities of their expansion ex-vivo, the use of the umbilical cord blood hematopoietic stem cells as well as the development of programs of gene therapy of cancer using hematopoietic stem cells [39, 40].

\section{TREATMENT OF FEMALE AND MALE INFERTILITY}

Cell technologies show promise for overcoming infertility and other problems associated with functional impairment of the reproductive system in humans, for whom conventional conservative or surgical treatment do not provide the desired effect $[12,33,38]$. For this purpose, the approaches to implantation of the cultures of germinal cells into the gonads are being elaborated, in particular in women the autologous ovarian stem cells are investigated, as well as directed differentiation of embryonic and somatic stem cells into gametes [4].

Today the dogma that the number of oocytes in women is laid still in the fetal period is disputed, as the reconstitution of germinal cells was shown in the adult ovary $[4,12,22,35]$. Thus, in 2004, two studies have confirmed that adult ovaries contain oocyte-producing stem cells that can be cultured in vitro to mature oocytes [11]. A group of researchers from the Massachusetts General Hospital of Harvard Medical School stated about the origin of germinal cells in adult female mammals from the bone marrow and their further encountering into the ovaries with the blood flow [21, 22]. However, the same group of researchers denied this fact in their later work, showing that in ovariectomized animals germinal cells in the adult body are not produced. But at the same time, the authors are of the opinion of a special relationship between the ovaries and the bone marrow, suggesting that the germinal cells produced in the ovaries can enter the bone marrow. In the experiments on mice it was shown that animals with the absence of primary follicles after myeloablation and allogeneic hematopoietic stem cell transplantation develop follicles with allogeneic oocytes. Concomitant immunosuppression allows allogeneic oocytes to develop both from the circulating germinal cells of the donor ovaries and from some types of stromal cells in the adult and fetal ovary due to the transplantation of donor immune cells, which as ovarian macrophages and T- lymphocytes accompany the development of germinal cells [21, 22] . There is also evidence of a positive effect of bone marrow transplantation on the reproductive function of the ovaries in females treated with chemotherapy for the treatment of malignant tumors [27].

It is known that the limited ability to fertilization is one of the clinical manifestations of Fanconi anemia. From 1976 to 2008, in 15 centers 578 patients with Fanconi anemia, who underwent bone marrow transplantation, were examined. In total, 10 of them got pregnant, 4 - twice. Pregnancy occurred in the period from 4 to 17 years after the hematopoietic stem cells transplantation. Based on this analysis, the scientists concluded that the restoration of normal function of the ovaries is a quite real task in patients with Fanconi anemia after hematopoietic stem cell transplantation, but still rarely feasible [33].

In 2003, for the first time the possibility of obtaining germinal cells, especially female, from embryonic cells was shown. The possibility to develop 0ocyte-like cells from embryonic stem cells was reported, although their functionality still leaves much to be elucidated [34]. It is also known that as gametogenesis can be induced in vitro, the same adult germinal cell may be returned to a state similar to pluripotent embryonic cells. Several laboratories obtained primordial germinal cells from embryonic stem cells in vitro [2]. But the scientists are the closest to the induction of differentiation of neogametogenesis from embryonic stem cells in men, in whom the own germinal cells are not detected. Although the results of these studies are still far from the introduction into clinical practice $[29,49]$.

The purpose of laboratory neogematogenesis is not only the use of artificially cultured gametes for infertility treatment, but also receive a laboratory model for more in-depth study of spermatogenesis and oogenesis $[13,28]$.

There is also evidence of regeneration of the endometrium in women after transplantation of the bone marrow hematopoietic stem cells. The approaches to intrauterine transplantation of endometrial stem cells in women with poor endometrial proliferative response to hormonal stimulation were also developed and implemented into the practice of in vitro fertilization.

\section{CREATION OF TISSUE-ENGINEERED CONSTRUCTS FOR GYNECOLOGY}

One of the most urgent problems of modern gynecology is the uterus transplantation as an alternative to surrogacy. Long-term experimental studies in this area have led to the introduction of this approach into clinical practice. In 2010, there was the first report of pregnancy after allogeneic uterus transplantation in experimental immunosuppression [10].

The world's first uterus transplantation was held by a group of doctors in Saudi Arabia in 2002, who transplanted the uterus of 26-yearold woman to a 46-year-old female patient. Transplanted uterus was normally functioning for 3 months and went through two menstrual cycles. After 99 days, the transplanted uterus had to be removed due to prolapse and necrosis [14, 24]. Today, a number of similar operations were carried out in Sweden and Turkey, but so far there is no evidence of pregnancy or childbirth after transplantation of donor uterus, and there remains a number of unresolved ethical issues in connection with the uterus donation and medical questions about the examination of donors and posttransplantation treatment of the recipient $[1,24]$.

Also a concept of the artificial womb for in vitro maturation of the fetus is widely discussed in the world. And in 2010, the scientists created $3 D$ artificial human ovary to mature human oocytes in the experiment. Theca and granulosa cells from antral follicles of women of reproductive age were planted on micromodelling gel and they organized themselves into complex $3 D$ microtissue. Immunohistochemistry and «live-dead» staining confirmed the identity of theca cells and their viability at 1 week. Putting granulosa cell spheroids or cumulus-0ocyte complexes on porous holes with theca cells resulted in the creation of artificial human ovary. Theca and granulosa cells organized themselves into complex microtissue, remaining viable in one week. At 72 hours after the creation of artificial construct of the human ovary, theca cells were completely surrounded by granulosa spheroids without stromal invasion or break. Polar body extrusion appeared in one of 3 cumulus-0ocyte complexes. Thus, these studies confirm that the creation of artificial human ovary with a self-organizing human theca and granulosa microtissues, aimed at its further use for in vitro fertilization and toxicological studies, is quite possible [26]. 


\section{PRENATAL STEM CELL \\ TRANSPLANTATION AND GENE THERAPY FOR INTRAUTERINE TREATMENT OF CONGENITAL GENETIC DISEASES OF THE FETUS}

Prenatal stem cell transplantation is a new and promising therapeutic approach for the treatment of genetic disorders, which is currently at the stage of transition from preclinical research to implementation in clinical practice. In the context of prenatal transplantation the multipotent adult stem cells from such sources as umbilical cord blood, amniotic fluid and fetal, embryonic and induced pluripotent stem cells are considered [44].

The first clinical experience indicates that congenital diseases, which lead to the development of severe immune deficiency, can be successfully treated in utero. At the same time, scientists succeeded only in the treatment of conditions, characterized by severe immune deficiency $[38,46,47,48]$. In this direction, the therapeutic strategies, implicating transplant modification, prenatal conditioning of the fetus, postnatal retransplantation after the prenatal induction of immune response, and fetal gene therapy using autologous fetal stem cells are considered. The use of non-hematopoietic stem cells (mesenchymal and pluripotent) likely will expand the range of indications for this new method of treatment [47]. It is proved that prenatal stem cell transplantation is most effective at the very early stages of gestation. The methods of intracoelomic injection of stem cells under the control of ultrasonography were developed [38, $46,48]$. In the experiment, scientists succeeded to carry out the prenatal reconstruction of trachea in fetal lambs, using amniotic stem cells [18].

Prenatal gene therapy implicates gene delivery to the cells and tissues during early fetal development in order to correct genetic defects before unrepairable tissue damage is formed. Unlike postnatal gene therapy, prenatal manipulations can deliver genes to the vast population of stem cells. Also, the early period of gestation allows the development of immune tolerance to the transgenic protein, which will allow the repeated postnatal gene therapy, if necessary [8].

Prenatal gene therapy is a potential alternative to gene transfer into the already formed lungs. At the same time, the issues of side-effects of these manipulations, the risk of oncogenic and degenerative processes in the fetus require deeper investigation [7].

\section{BANKING AND APPROACHES TO THE CLINICAL APPLICATION OF THE ENDOMETRIAL STEM CELLS, MAMIMARY AND AMNIOTIC FLUID STEM CELLS}

The presence of cells, having genotypic, phenotypic and functional characteristics of somatic stem cells and expressing several endothelial markers, mainly CD146 ${ }^{+}$PDGFRbeta ${ }^{+}$, with the ability to differentiate into the endometrial glandular epithelial cells, endothelial cells and stromal cells have been recently detected in the endometrium. Endometrial epithelial progenitor cells include mesenchymal and endothelial cells and improve the recovery of endometrium after menstruation. Therapeutic strategies for the use of these cells in the treatment of diseases are currently on the stages of experimental and early clinical studies [5, 17]. In 2012, the first clinical trial (1-2 phase) to evaluate the safety and efficacy of endometrial stem cells in the treatment of critical limb ischemia launched in USA. Also in USA, Europe and India the cryobanks, specializing in the cryopreservation of endometrial stem cells were created.

The recently described mammary and amniotic fluid stem cells are also of great scientific interest. Mammary stem cells were found in breast epithelium and breast carcinoma [16]. Their biological role is yet poorly elucidated, it is believed that these cells are involved in the development and homeostasis of the mammary gland, as well as carcinogenesis and further studies will enable to develop new approaches to the prevention and treatment of breast cancer [16].
Stem cells, derived from amniotic fluid, are extremely attractive for the purposes of tissue engineering and prenatal correction of fetal anomalies, since they have a very high proliferative potential and the ability to multilineage differentiation [19].

\section{CRYOPRESERVATION OF REPRODUCTIVE CELLS AND TISSUES}

The high incidence of infertility in both men and women after chemotherapy and/or radiation therapy, aimed at treating the underlying disease, led to the search for the effective methods of fertility preservation in cancer patients. It is known, that gonadotoxic therapy in childhood can lead to infertility in adulthood. Currently existing techniques of maintenance of fertility in cancer patients implicate the cryopreservation of reproductive cells and tissues as well as embryos. There is quite optimistic data on the ovarian tissue cryopreservation, since actually at least 25 children were born in the world after retransplantation of frozen ovarian tissue.

In 2012, the first case of pregnancy in Germany after retransplantation of frozen ovarian tissue was published: a 25-year-old woman in 2003 was exposed to chemotherapy and mediastinal irradiation due to Hodgkin's Iymphoma. After 2 years, the patient had a relapse. She was conducted the collection of ovarian tissue, performed laparoscopically, with its subsequent cryoconservation, and then she was administered highdose chemotherapy and hematopoietic stem cell transplantation. The patient had a 5-year remission, but during this period she could not get pregnant. A woman was carried out the laparoscopic reimplantation of frozen autologous ovarian tissue, implanted in the peritoneal fold in the ovarian fossa of the right abdominal wall. After 3 months, the menopausal symptoms disappeared, and the first menstruation occurred. After 6 months, after two menstrual cycles, the assignment of small doses of follicle-stimulating hormone led to the development of the dominant follicle in the tissue graft. Ovulation was induced by human chorionic gonadotropin, after which she became pregnant naturally. Pregnancy was normal and ended with the birth of a healthy baby by means of cesarean section. Histological examination confirmed that the ovarian tissue autograft contained follicles at different stages of development, while her primary ovaries did not show any reproductive potential [32].

However, to date, there are no reports of pregnancies after retransplantation of ovarian tissue, frozen before puberty, but the presence of a large number of follicles in the ovaries of young girls makes predisposition to a positive prognosis for such manipulations [3, 32, 41].

In 2012, the journal "Lancet» published a case of induction of puberty in a girl, which at 10 years of age (before puberty) was performed autologous ovarian tissue cryopreservation. The child was expecting the treatment of the sickle cell anemia, which included highdose chemotherapy and stem cell transplantation. Such treatment was characterized by a high risk of infertility development in adulthood. Therefore, the child was held laparoscopic ovariectomy and ovarian tissue was frozen, cut into 23 fragments. Child's height in that period was $142 \mathrm{~cm}$, weight - $31 \mathrm{~kg}$, no signs of puberty were observed.

After 27 months at the age of 13 the girl was performed autologous transplantation of ovarian tissue for the induction of puberty. Before autologous transplantation of ovarian tissue the child's bone age coincided 13 years, but her height was $156 \mathrm{~cm}$ and weight $-39 \mathrm{~kg}$. In 2007, the girl was transplanted 3 slices of the autologous ovarian tissue in the subcutaneous tissue of the abdominal wall on the left between the skin and the muscular layer of the stomach. 2 months after transplantation, the beginning of maturation of the mammary glands on both sides was marked, and after 8 months the beginning of menstruation occurred. After 3 years and 3 months after autologous transplantation of ovarian tissue patient's height was $172 \mathrm{~cm}$, weight $52 \mathrm{~kg}$. Also the complete development of the mammary glands was noted.

To preserve fertility in men or boys before gonadotoxic therapy the cryopreservation of sperm and testicular tissue may be conducted. 
Experimental studies in animals proved the appearance of healthy offspring after implantation of frozen suspension or grafts of the testicular tissue $[3,41]$.

\section{RECONSTRUCTIVE BREAST SURGERY}

In recent years, the autologous adipose tissue is increasingly used in plastic surgery of the breast, fulfilling not only the functions of biofiller, but also due to the high content of mesenchymal stem cells providing endocrine, exocrine and paracrine functions. The results of long-term observation of the patients, who underwent reconstructive breast surgery, using autologous adipose tissue, are not yet available, but literary data, published to date, demonstrate the safety of this approach [30].

\section{CONCLUSIONS}

THUS, THESE DATA INDICATE THE ACTIVE INTRODUCTION OF CELLULAR AND GENE TECHNOLOGIES IN THE FIELD OF REPRODUCTION, OBSTETRICS AND GYNECOLOGY, WHAT SIGNIFICANTLY EXPANDS THE ARSENAL OF THERAPEUTIC AGENTS FOR MEDICAL PRACTITIONERS AND IN NEAR FUTURE WILL ENABLE TO DEVELOP NEW APPROACHES TO THE TREATMENT OF DISEASES, ONCE CONSIDERED INCURABLE.

\section{REFERENCES}

1. Akar M., Ozkan O., Erdogan O. et al. Uterus transplantation from a deceased donor // Fertil. Steril. - 2013. - http://www.ncbi.nlm.nih.gov/pubmed/23880349.

2. Baughman J., Geijsen N. In vitro generation of germ cells: new techniques to solve current issues //Ann. NY Acad. Sci. - 2005. - 1061. - P. 33-40.

3. Binart N., Sauvat F. Cryopreserved ovaries: models of experimental grafting // Biol. Aujourdhui. - 2011. - 205, № 4. - P. 235-243.

4. Bukovsky A., Copas P., Virant-Klun I. Potential new strategies for the treatment of ovarian infertility and degenerative diseases with autologous ovarian stem cells // Expert. Opin. Biol. Ther. - 2006. - 6, № 4. - P. 341-365.

5. Cervellor l., Gil-Sanchis C., Aymara Mas et al. Human Endometrial Side Population Cells Exhibit Genotypic, Phenotypic and Functional Features of Somatic Stem Cells // PLoS One. - 2010. - 5, № 6. - P. 1-15.

6. Chao K., Yang H., Chen M. Human umbilical cord mesenchymal stem cells suppress breast cancer tumourigenesis through direct cell-cell contact and internalization // J. Cell. Mol. Med. - 2012. - 16, № 8. - P. 1803-1815.

7. Conese M., Ascenzioni F., Boyd A. et al. Gene and cell therapy for cystic fibrosis: from bench to bedside // J. Cyst. Fibros. - 2011. - 10, suppl 2. - P. 114 - 128.

8. David A.L., Waddington S.N. Candidate diseases for prenatal gene therapy // Methods Mol. Biol. - 2012. - 891. - P. 9 - 39.

9. Demirer T., Barkholt L., Blaise D. et al. Transplantation of allogeneic hematopoietic stem cells: an emerging treatment modality for solid tumors. Nat. Clin. Pract. Oncol. - 2008. - 5, № 5. - P. $256-267$.

10. Díaz-García C., Akhi S., Wallin A. et al. First report on fertility after allogeneic uterus transplantation // Acta Obstet. Gynecol. Scand. - 2010. - 89, № 11. P. $1491-1494$

11. Du H., Taylor H. Stem cells and reproduction. Curr. Opin. Obstet. Gynecol. - 2010. - 22, № 3. - P. $235-241$.

12. Dunlop C., Telfer E., Anderson R. Ovarian stem cells - potential roles in infertility treatment and fertility preservation // Maturitas. - 2013. - http://www.ncbi.nlm. nih.gov/pubmed/?term=0varian+stem+cells++potential+roles+in+infertility+treatment+and+fertility+preservation.

13. Easley C., Simerly C., Schatten G. Stem cell therapeutic possibilities: future therapeutic options for male-factor and female-factor infertility? // Reprod. Biomed. Online. - 2013. - 27, № 1. - P. 75 - 80

14. Fageeh W., Raffa H., Jabbad H. et al. Transplantation of the human uterus // Int. J. Gynaecol. Obstet. - 2002. - 76, № 3. - P. 245 - 251.

15. Fish J. Fertility preservation for adolescent women with cancer // Adolesc. Med. State. Art. Rev. - 2012. - 23, № 1. - P. 111 - 122.

16. Fridriksdottir A., Petersen 0., Rønnov-Jessen L. Mammary gland stem cells: current status and future challenges // Int. J. Dev. Biol. - 2011. - 55, №7-9. P. $719-729$.

17. Gargett C.E., Masuda H. Adult Stem Cells in the Endometrium // Mol. Hum. Reprod. - 2010. - 16, № 11. - P. 818-834

18. Gray F., Turner C., Ahmed A. et al. Prenatal tracheal reconstruction with a hybrid amniotic mesenchymal stem cells-engineered construct derived from decellularized airway // J. Pediatr. Surg. - 2012. - 47, № 6. - P. 1072-1079.

19. Hartmann K., Raabe 0., Wenisch S. et al. Amniotic fluid derived stem cells give rise to neuron-like cells without a further differentiation potential into retina-like cells // Am. J. Stem Cells. - 2013. - 2, № 2. - P. 108-118.

20. Hu W., Wang J., He X. et al. Human umbilical blood mononuclear cell-derived mesenchymal stem cells serve as interleukin-21 gene delivery vehicles for epithelial ovarian cancer therapy in nude mice // Biotechnol. Appl. Biochem. - 2011. - 58, № 6. - P. 397-404.

21. Johnson J., Bagley J., Skaznik-Wikiel M. et al. Oocyte generation in adult mammalian ovaries by putative germ cells in bone marrow and peripheral blood // Cell. 2005. - 122. - P. 303-315.

22. Johnson J., Canning J., Kaneko T. et al. Germline stem cells and follicular renewal in the postnatal mammalian ovary // Nature. - 2004. - 428. - P.145-150.

23. Kang N.H., Yi B.R., Lim S.Y. et al. Human amniotic membrane-derived epithelial stem cells display anticancer activity in BALB/C female nude mice bearing disseminated breast cancer xenografts // Int. J. Oncol. - 2012. - 40, № 6. - P. 2022-2028.

24. Kisu I., Banno K., Mihara M. et al. Current status of uterus transplantation in primates and issues for clinical application // Fertil. Steril. - 2013. - 100, № 1. P. 280-294.

25. Kisu I., Mihara M., Banno K. et al. Risks for Donors in Uterus Transplantation // Reprod. Sci. - 2013.- http://www.ncbi.nlm.nih.gov/pubmed/23793471.

26. Krotz S.P., Robins J.C., Ferruccio T.M. et al. In vitro maturation of oocytes via the pre-fabricated self-assembled artificial human ovary // J. Assist. Reprod. Genet. 2010. - 27, №12. - P. $743-750$.

27. Lee H.J., Selesniemi K., Niikura Y. et al. Bone marrow transplantation generates immature oocytes and rescues long-term fertility in a preclinical mouse model of chemotherapy-induced premature ovarian failure // J. Clin. Oncol. - 2007. - 25, № 22. - P. 3198-3204.

28. Li P., Hu H., Yang S. et al. Differentiation of induced pluripotent stem cells into male germ cells in vitro through embryoid body formation and retinoic acid or testosterone induction // Biomed Res Int. - 2013. - http://www.ncbi.nlm.nih.gov/pubmed/23509752.

29. Maggiulli R., Neri Q., Monahan D. et al. What to do when ICSI fails // Syst. Biol. Reprod. Med. - 2010. - 56, № 5. - P. $376-387$. 
30. Mátrai Z., Pesthy P., Gulyás G. et al. Autologous fat transplantation in the modern reconstructive surgery of breast cancer // Orv. Hetil. - 2012. - 153, № 46. P. 1816-1831.

31. Möbus V., Wandt H., Frickhofen N. et al. Phase III trial of high-dose sequential chemotherapy with peripheral blood stem cell support compared with standard dose chemotherapy for first-line treatment of advanced ovarian cancer: intergroup trial of the AG0-Ovar/AIO and EBMT // J. Clin. Oncol. - 2007. - 25, № 27. P. 4187-4193.

32. Müller A. Keller K., Wacker J. et al. Retransplantation of cryopreserved ovarian tissue: the first live birth in Germany // Dtsch. Arztebl. Int. - 2012. - 109, № 1-2. P. 8-13.

33. Nabhan S., Bitencourt M., Duval M. et al. Fertility recovery and pregnancy after allogeneic hematopoietic stem cell transplantation in Fanconi anemia patients // Haematologica. - 2010. - 95, № 10. - P. 1783-1787.

34. Conti M., Giudice L. From stem cells to germ cells and back again // Nature medicine. - 2008. - 14, № 11. - P. 1188-1190.

35. Oktem 0., Oktay K. Stem cells: a perspective on oocytes // Ann. NY Acad. Sci. - 2008. - 1127. - P. 20-26.

36. Pedrazzoli P., Martinelli G. Proceedings of the 36th annual Meeting of the European Group for Blood and Marrow Transplantation; 2010 March 21-24; Vienna, Austria. NPG; 2010.

37. Pedrazzoli P., Rosti G., Secondino S et al. High-dose chemotherapy with autologous hematopoietic stem cell support for solid tumors in adults // Semin. Hematol. 2007. - 44, № 4. - P. 286-295.

38. Perillo A., Bonanno G., Pierelli L. et al. Stem cells in gynecology and obstetrics // Panminerva Med. - 2004. - 46, №1. - P. 49-59.

39. Perillo A., Ferrandina G., Pierelli L. et al. Stem cell-based treatments for gynecological solid tumors // Eur. Rev. Med. Pharmacol. Sci. - 2005. - 9, № 2. - P. 93-102.

40. Perillo A., Pierelli L., Scambia G. et al. The role of hematopoietic stem cells in the treatment of ovarian cancer // Panminerva Med. - 2002. - 44, № 3. - P. 197-204.

41. Poirot C., Schubert B. Fertility preservation in prepubertal children // Bull. Cancer. - 2011. - 98, № 5. - P. 489-499.

42. Poirot ., Abirached F., Prades M. et al. Induction of puberty by autograft of cryopreserved ovarian tissue // Lancet. - 2012. - 379. - P. 588.

43. Ringdén 0. Immunotherapy by allogeneic stem cell transplantation // Adv. Cancer Res. - 2007. - 97. - P. 25-60.

44. Roybal J., Laje P., Vrecenak J. et al. Use of manipulated stem cells for prenatal therapy // Methods Mol. Biol. - 2012. - 891. - P. 169-181.

45. Sun M., Wang S., Li Y. et al. Adipose-derived stem cells improved mouse ovary function after chemotherapy-induced ovary failure // Stem Cell Res. Ther. - 2013. 4, №4. - P. 80 .

46. Surbek D., Gratwohl A., Holzgreve W. In utero hematopoietic stem cell transfer: current status and future strategies // Eur. J. Obstet. Gynecol. Reprod. Biol. - 1999. 85, № 1. - P. 109-115.

47. Surbek D., Holzgreve W. Prenatal stem cell transplantation: from bench to bedside // Ther. Umsch. - 2002. - 59, № 11. - P. 619-623.

48. Surbek D., Holzgreve W., Nicolaides K. Haematopoietic stem cell transplantation and gene therapy in the fetus: ready for clinical use? // Hum. Reprod. Update. 2001. - 7, № 1. - P. 85-91.

49. Yang R., Xiong C. Application prospect of adult stem cells in male infertility // Zhonghua Nan Ke Xue. - 2013. - 19, № 5. - P. 468-471. 